\title{
Increased Mauthner cell activity and escaping behaviour in seabream fed long-chain PUFA
}

\author{
Tibiábin Benítez-Santana*, Eduardo Juárez-Carrillo, Mónica Beatriz Betancor, Silvia Torrecillas, \\ María José Caballero and María Soledad Izquierdo \\ Grupo de Investigación en Acuicultura, Universidad de Las Palmas de Gran Canaria, Instituto Canario de Ciencias \\ Marinas, PO 56, 35200 Telde, Las Palmas, Canary Islands, Spain
}

(Received 10 January 2011 - Revised 6 April 2011 - Accepted 11 April 2011 - First published online 30 June 2011)

\begin{abstract}
There is limited information on the specific effects of long-chain PUFA (LCPUFA) on neuron development and functioning. Deficiency of those essential fatty acids impairs escape and avoidance behaviour in fish, where Mauthner cells (M-cells) play a particularly important role in initiating this response. Gilthead seabream larvae fed two different LCPUFA profiles were challenged with a sonorous stimulus. Feeding $n$ - 3 LCPUFA increased the content of these fatty acids in fish tissues and caused a higher number of larvae to react to the stimulus with a faster burst swimming speed response. This faster startle response in fish fed $n-3$ LCPUFA was also associated with an increased immune-positive neural response, particularly in M-cells, denoting a higher production of acetylcholine. The present study shows the first evidence of the effect of $n$-3 LCPUFA on the functioning of particular neurons in fish, the M-cells and the behaviour response that they modulate to escape from a sound stimulus.
\end{abstract}

Key words: Mauthner cells: Fish larvae behaviour: Essential fatty acids: DHA: Burst swimming speed

Despite $n$-3 long-chain PUFA (LCPUFA) have been long recognised as being important for brain development and function, little is known on their specific effects on neuron activity in relation to behaviour. $n$-3 LCPUFA play important roles in neural growth, development of synaptic processing of neural cell interaction and expression of genes that regulate cell differentiation and growth ${ }^{(1)}$. Essential fatty acid metabolism can influence many aspects of brain development, including neuronal migration, axonal and dendritic growth and the creation, remodelling and pruning of synaptic connections $^{(2,3)}$. Animal studies have shown that both neural integrity and function can be permanently disrupted by deficits of $n-6$ and $n$ - 3 fatty acids during fetal and neonatal development ${ }^{(4,5)}$. While both $n-6$ and $n-3$ fatty acids are required, the $n-3$ fatty acids, such as DHA (22:6n-3), appear to play a special role in highly active sites such as synapses and photoreceptors and deficiencies have particularly been linked to visual and cognitive deficits ${ }^{(6,7)}$.

In marine fish, $n$-3 LCPUFA are essential and play very important physiological roles ${ }^{(8,9)}$. Specifically, DHA and EPA (20:5n-3) acids must be supplied in the diet and function as critical structural and physiological components of the cell membranes of most tissues that are necessary for fish growth, welfare, survival and development ${ }^{(10,11)}$. In particular, DHA has been found to be required for the normal development of the nervous system and sensory organs, such that the larval brain and eye fatty acid compositions reflect the diet ${ }^{(12,13)}$. Moreover, DHA deficiency impairs vision in juvenile herring (Clupea harengus) ${ }^{(14)}$. Therefore, dietary fatty acid contents could potentially affect behaviour, stress reactions or pain and comfort, despite the lack of studies on this subject in fish. Recently, dietary fatty acids have been found to affect escape and avoidance behaviour in fish larvae after a sound or visual stimulus ${ }^{(13,15)}$. Fish can elude predatory attacks by producing a stereotyped escape behaviour, which is characterised by a rapid and powerful unilateral bending of the body and caudal fin that involves most of its somatic musculature $^{(16)}$. This behaviour is initiated by the activation of the Mauthner cells (M-cells).

M-cells integrate diverse sensory inputs ${ }^{(17,18)}$ and are able to reset swimming rhythms in the course of its initiation of escape behaviours ${ }^{(19)}$. In chronic recordings of freely swimming intact fish, the M-cells have been shown to fire an action potential at the initiation of C-start responses ${ }^{(20-23)}$. Because the axons of each M-cell decussate, the firing of one leads to a contraction of the trunk musculature that is contralateral to the cell soma ${ }^{(20,24)}$. To date there is no evidence of an effect of the essential fatty acids on M-cell activity. Therefore, the aim of the present study was to better understand the effect of dietary $n-3$ LCPUFA on fish escape

Abbreviations: LCPUFA, long-chain PUFA; M-cells, Mauthner cells.

*Corresponding author: T. Benítez-Santana, fax +34 928132908, email tibi.benitez.santana@gmail.com 
and avoidance behaviour and neural function. For that purpose the effect of two different lipid sources, with different $n$-3 LCPUFA content, fed to gilthead seabream (Sparus aurata) during early larval and brain development on the fish reaction to a sonorous stimulus and M-cells activity was investigated. M-cell activity was determined by choline acetytransferase distribution by immuno-labelling as a marker of cholinergic neuron density, since the cholinergic neurotransmission system has been found to be sensitive to dietary $n$-3 PUFA in rats $^{(25)}$.

\section{Material and methods}

All animal studies complied with the guidelines for animal experimentation of our laboratories and were approved by the institutional review boards.

\section{Experimental conditions}

A total of 6600 gilthead seabream larvae of $22 \mathrm{~d}$ of age (posthatch) $(5.06$ (SD 0.59) $\mathrm{mm}$ in standard length) were randomly distributed into six 170 litres fibre glass cylindrical tanks and were fed in triplicate with two experimental diets. Diets differed only in the lipid source to obtain different fatty acid profiles. Lipid sources were fish oil rich in $n$-3 LCPUFA and soyabean oil rich in linoleic acid $(18: 2 n-6)$. The diets were analysed for crude lipid content and fatty acid composition (Table 1). Microdiets were prepared according to Atalah et $a{ }^{(26)}$. No significant differences were found in the dry lipid content (20.09; $P>0 \cdot 05$.). All tanks were supplied with filtered seawater $\left(34 \mathrm{ppm}\right.$ salinity) at $19-20^{\circ} \mathrm{C}$, constant aeration $(125 \mathrm{ml} / \mathrm{min})$, seawater flow $(0.4$ litres $/ \mathrm{min}$ at the beginning to 1.0 litres $/ \mathrm{min}$ at the end) and artificial light $(12 \mathrm{~h}$ photoperiod). Feeds $(2.5 \mathrm{~g} / \mathrm{tank}$ per d) were manually supplied fourteen times per d every $45 \mathrm{~min}$ during the light period.

\section{Swimming speed behaviour}

The swimming speed of the larvae from each tank was determined at 23, 27 and $34 \mathrm{~d}$ of age in a 1 litre black wall glass beaker $(10 \mathrm{~cm}$ diameter) keeping a water depth of $4 \mathrm{~cm}$. Each larva was transferred from the feeding tanks to the glass beaker and then video-recorded using a Sony digital video camera (DCR-TRV27; Sony, Tokyo, Japan). After recording for $30 \mathrm{~s}$, the larva was scared by a sound stimulus to induce a startle response and determine a burst swimming speed. Consistent sound stimuli were produced using a steel nut ${ }^{(13)}$. Sound stimuli were provided three times at $10 \mathrm{~s}$ intervals for each larva. Afterwards, larval standard length was measured by a profile projector (Nikon V-12A; Nikon, Tokyo, Japan). This procedure was repeated using ten individuals from each rearing tank. Frame-by-frame video image analysis was conducted to calculate burst swimming speed ${ }^{(13,15)}$. Burst swimming speed was analysed only when the larva showed an obvious startle response. The fastest movement always appeared on the first frames after providing a stimulus as it occurs in younger larvae ${ }^{(13)}$. The speed was presented as a
Table 1. Fatty acid composition of total lipids of gilthead sea bream larvae fed with fish oil and soyabean oil microdiets (\% total determined fatty acids)

\begin{tabular}{|c|c|c|}
\hline Fatty acids & Fish oil diet & Soyabean diet \\
\hline $14: 0$ & 0.53 & 0.85 \\
\hline $14: 1 n-7$ & 0.02 & 0.04 \\
\hline $14: 1 n-5$ & 0.16 & 0.05 \\
\hline $15: 0$ & 0.54 & 0.22 \\
\hline $15: 1 n-5$ & ND & 0.03 \\
\hline $16: 0$ ISO* & 0.06 & 0.03 \\
\hline $16: 0$ & 23.37 & 17.94 \\
\hline $16: 1 n-7$ & 6.83 & 0.48 \\
\hline $16: 1 n-5$ & 0.38 & 0.06 \\
\hline $16: 2 n-4$ & 1.09 & 0.08 \\
\hline $17: 0$ & 1.22 & 0.26 \\
\hline $16: 3 n-4$ & 0.29 & 0.09 \\
\hline $16: 3 n-3$ & 0.03 & 0.02 \\
\hline $16: 3 n-1$ & 0.07 & 0.04 \\
\hline $16: 4 n-3$ & 0.58 & $0 \cdot 11$ \\
\hline $16: 4 n-1$ & 0.16 & 0.08 \\
\hline $18: 0$ & $2 \cdot 38$ & 1.92 \\
\hline $18: 1 n-9+n-7$ & $12 \cdot 11$ & $19 \cdot 65$ \\
\hline $18: 1 n-5$ & 0.18 & 0.46 \\
\hline $18: 2 n-6$ & 9.35 & $34 \cdot 11$ \\
\hline $18: 2 n-4$ & 0.17 & ND \\
\hline $18: 3 n-6$ & 0.14 & ND \\
\hline $18: 3 n-4$ & ND & $2 \cdot 40$ \\
\hline $18: 3 n-3$ & ND & 1.47 \\
\hline $18: 4 n-3$ & 1.26 & 0.07 \\
\hline $18: 4 n-1$ & 0.14 & 0.02 \\
\hline $20: 0$ & 0.07 & $0 \cdot 17$ \\
\hline $20: 1 n-9+n-7$ & 2.75 & 1.84 \\
\hline $20: 1 n-5$ & 0.22 & 0.06 \\
\hline $20: 2 n-9$ & 0.07 & 0.03 \\
\hline $20: 2 n-6$ & 0.22 & 0.14 \\
\hline $20: 3 n-6$ & 0.12 & ND \\
\hline $20: 4 n-6$ & 1.06 & 0.45 \\
\hline $20: 3 n-3$ & 0.31 & 0.22 \\
\hline $20: 4 n-3$ & 0.61 & 0.06 \\
\hline $20: 5 n-3$ & $12 \cdot 73$ & 4.97 \\
\hline $22: 1 n-11$ & 0.58 & 0.28 \\
\hline $22: 1 n-9$ & 0.36 & 0.13 \\
\hline $22: 4 n-6$ & 0.09 & 0.09 \\
\hline $22: 5 n-6$ & 0.24 & 0.11 \\
\hline $22: 5 n-3$ & 0.49 & 0.07 \\
\hline $22: 6 n-3$ & 13.89 & $10 \cdot 91$ \\
\hline
\end{tabular}

function of the standard length of each individual to avoid larval size interference ${ }^{(13,15)}$.

\section{Biochemical analyses}

At the end of the study the larvae were sampled for lipid and fatty acid composition of total lipids. The lipids were extracted by chloroform-methanol mixture ${ }^{(27)}$. Methyl esters of fatty acids were prepared by transesterification with $1 \%$ sulphuric acid and methanol using heneicosanoic acid (21: 0; $10 \%$ of total lipids) as an internal standard ${ }^{(28)}$. The fatty acid methyl esters obtained were separated by a GC (Shimadzu GC-14a, Kyoto, Japan) run using the operating conditions described previously ${ }^{(29)}$, quantified by flame ionisation detection and identified by comparison with well-characterised external standards. 


\section{Immunofluorescence study}

A total of thirty larvae per tank ( $n$ 90) were collected and fixed in $10 \%$ buffered formalin at the end of the experiment. Each larva head was mounted in a gelatin block in a horizontal orientation to obtain better visualisation of neuronal structures. Gelatin-embedded larva head blocks were cryoprotected in $30 \%$ sucrose and serially cut on a Slee Mainz cryostat at $10 \mu \mathrm{m}$. Each gelatin section for immunofluorescence slides was collected on gelatin-coated slides. The antibody was tested to determine the optimal working concentration and quality of the signal and seabream larvae were processed for the demonstration of immunoreactivity. The slides were covered with $5 \%$ rabbit serum and $0 \cdot 2 \%$ Triton in PBS for $1 \mathrm{~h}$. Incubations with anti-choline acetyltransferase primary antibody (1:250; Millipore, Billerica, MA, USA) were carried out for $48 \mathrm{~h}$ at $4^{\circ} \mathrm{C}$ in a $0 \cdot 1 \mathrm{M}$ (PBS) solution with $0 \cdot 1 \%$ Triton X-100 and 2\% goat serum (Vector). As a secondary antibody we used a anti-goat IgG FITC conjugate (1:250, antibody developed in rabbit affinity-isolated antigen-specific antibody (Sigma, Madrid, Spain) diluted in PBS and applied for $1 \mathrm{~h}$ in a dark room at room temperature. A propidium iodide complex at a concentration of $1: 10^{4}$ was applied for 5-10 min at room temperature and was used for nuclei contrast staining. In order to see the M-cell green immunofluorescence, a Zeiss LSM 510 confocal system (Zeiss, Thornwood, NY, USA) was used. In order to prevent fluorescence data from being compromised, in each batch of samples processed all treatments were always included. Negative controls were run by replacing each primary antibody by PBS to test for the specificity of an antibody involved.

\section{Statistical treatment of data}

Data were statistically analysed with the SPSS software (SPSS 11.5 for Windows; SPSS, Inc., Chicago, IL, USA). The values are reported as means and standard deviation. The normality of the variable distribution was verified using Levene's test, not requiring any transformation. The values of fatty acid levels were expressed as means and standard deviation, and Student's $t$ test was employed to compare the results of fatty acids and behavioural studies. Significance was accepted at $P<0.05$.

\section{Results}

Under the stimulus challenges conducted during the study, the number of larvae (twenty larvae/diet per challenge) that reacted to the sound stimulus was related to larval age and diet. Thus, at $23 \mathrm{~d}$ of age a low percentage of larvae reacted to the stimulus, whereas at $27 \mathrm{~d}$ this number significantly $(P<0.03)$ increased (Fig. 1 (a)). At $32 \mathrm{~d}$, a similar proportion of larvae reacted when they were fed fish oil, whereas the percentage of reacting larvae was lower in those fed soyabean oil ( $P<0 \cdot 05$; Fig. 1 (a)).

In larvae fed fish oil, burst swimming speed after sound stimuli increased with age being highest in larvae of $34 \mathrm{~d}$ $(P<0.03$; Fig. 1 (b)). However, in larvae fed soyabean oil
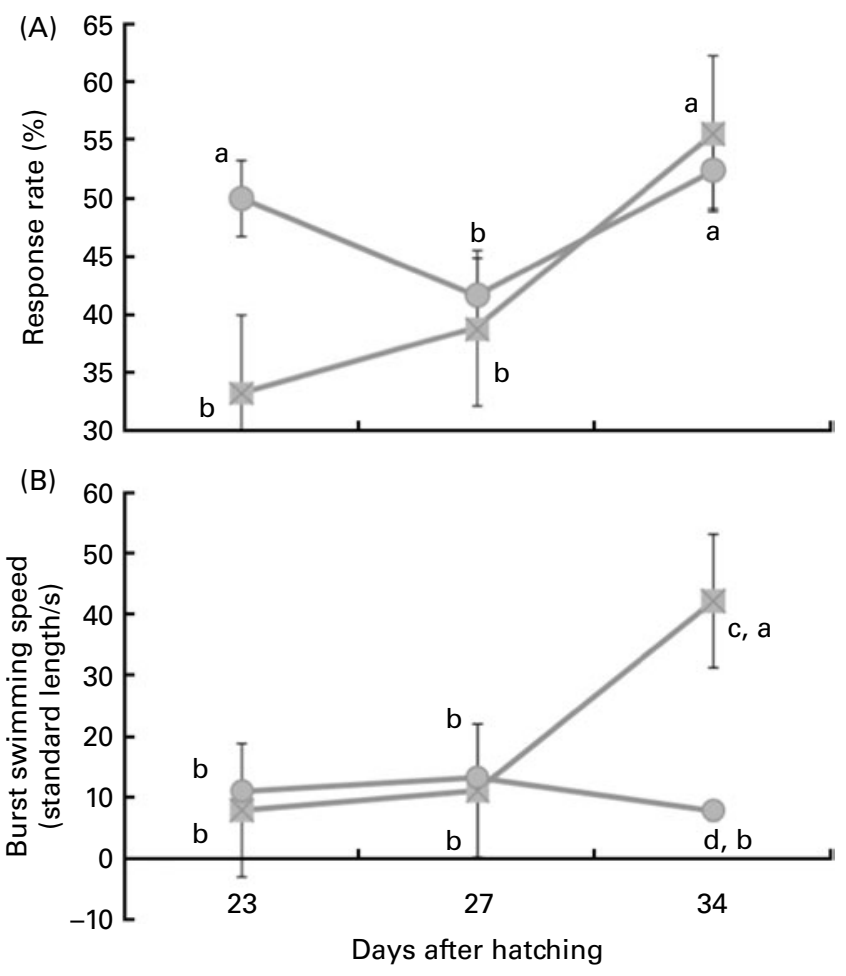

Fig. 1. Larval reaction after the sound stimuli along larval development. (A) Number (\%) of reacting sea bream larvae for each experimental group after the sound stimuli fed diets containing fish oil $(₫)$ and soyabean oil $(0)$. (B) Burst swimming speed (standard length/s) in sea bream larvae fed microdiets enriched with different types of lipids: fish oil $(\mathbb{\Xi})$ and soyabean oil (०). a,b Mean values with unlike letters were significantly different between animals of same treatment $(n 30, P<0.05) .{ }^{\mathrm{c}, \mathrm{d}}$ Mean values with unlike letters were significantly different between animals of different treatment ( $n 30$, $P<0.05)$.

burst swimming speed only increased at $27 \mathrm{~d}$ in comparison with $23 \mathrm{~d}$ and it was even reduced in 34-d-old larvae when they were fed soyabean oil (Fig. 1 (b)). Therefore, at day 34 burst swimming speed after sound stimulus of larvae fed fish oil was significantly higher $(P<0 \cdot 02)$ than that of fish fed soybean oil (Fig. 1 (b)).

Confocal microscopy analysis showed a greater acetylcholine immunopositive response (green fluorescence) in larvae fed the fish oil microdiet than in those fed the soyabean oil microdiet $(P<0.03$; Fig. 2). Fluorescence quantification showed a significantly higher immunoposititve response in larvae fed fish oil than in larvae fed the soyabean oil microdiet (Fig. 3).

The larvae fed the fish oil diet showed the highest DHA and EPA $(P<0.03)$ content in the whole body (Table 2$)$. The fatty acid composition of larval fish (Table 2 ) at $36 \mathrm{~d}$ after hatching showed that larvae fed with soyabean oil microdiets lost $n$-3 LCPUFA content (both EPA and DHA in the same proportion) in comparison with larvae fed with a fish oil microdiet in which the content of DHA and EPA $(P<0.004)$ is higher in whole body compared with fish fed soyabean oil. Larvae fed the fish oil microdiet showed a reduction in monoenoics and unsaturated fatty acids, while showing the highest content of $n$-3 fatty acids. Larvae fed with soyabean oil microdiets 


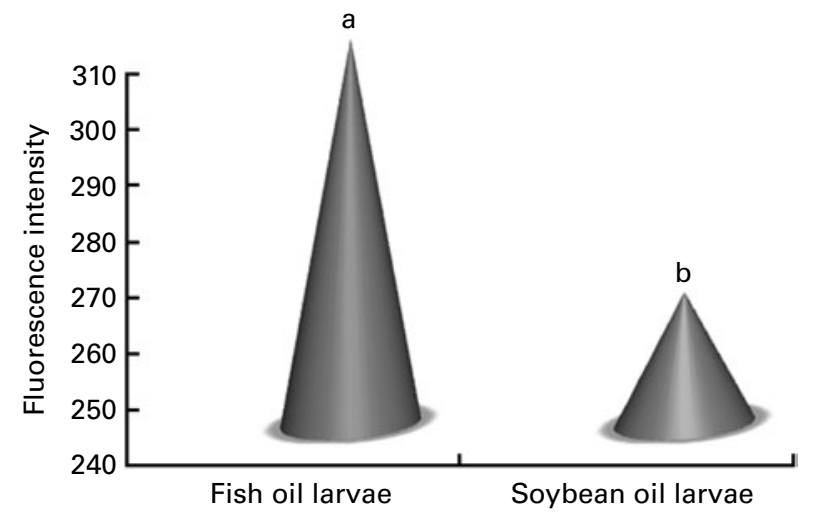

Fig. 2. Quantification of green fluorescent intensity by confocol microscopy according to the immunopositive response of Mauthner cells in sea bream larvae fed microdiets with fish oil and soyabean oil. ${ }^{a, b}$ Mean values were significantly different between animals of different treatment $(n 30, P<0.05)$.

were rich in fatty acids of the $n-6$ series, particularly $18: 2 n-6$ showed a significant reduction $(P<0.04)$ compared with levels found in fish fed the fish oil diet. Soyabean oil larvae showed a higher content of monoenoics and SFA, which may reduce membrane fluidity. These fatty acid incorporation results demonstrated good assimilation of the diet by the larvae.

\section{Discussion}

In the present study, the reduction in dietary $n$ - 3 PUFA caused a significant reduction in the contents of these fatty acids in the fish. In gilthead seabream, brain fatty acid composition is also modified by the $n$ - 3 LCPUFA content of the diet ${ }^{(13)}$, and therefore, being necessary for the normal development of nervous system and sensory organs, these fatty acids could affect physiological functions in the brain. In fact, a diet unbalanced in $n-3$ PUFA may cause changes in cell permeability and synaptic membrane fluidity ${ }^{(30)}$, or modifications in the number and affinity of receptors, in the function of ion channels and on the activity of neurotransmitters ${ }^{(31)}$. Thus, alterations in brain fatty acid composition could potentially affect behaviour.

An important behaviour to escape from predation is the startle response, which is initiated by a sudden stimulus and results in rapid reaction. In the present study, the substitution of soyabean oil by fish oil in microdiets for larval gilthead seabream markedly increased $n-3$ LCPUFA content in fish tissues and affected fish behaviour in terms of the startle response to a sonorous stimulus. Thus, during fish development, a higher but not statistically different number of larvae reacted to the stimulus when they were fed fish oil, rich in $n-3$ LC-PUFA. Moreover, a $n-3$ LC-PUFA increase in the diet also led to a faster swimming speed burst in those larvae that reacted to the sonorous stimulus at $32 \mathrm{dph}$. Therefore, dietary reduction in $n$-3 LC-PUFA impaired fish larval response to the stressor, reducing the escape behaviour in larvae with a lower content of $n$-3 LC-PUFA in their body tissues. These results highlight the important role of these fatty acids in response to a sonorous stimulus, in agreement with their importance for sensory organ functioning ${ }^{(32)}$. In contrast with the present study, younger and less developed gilthead seabream burst swimming response to a sound stimulus was not affected by dietary $n-3$ LCPUFA, whereas they had a high burst swimming speed after a light stimulus ${ }^{(13)}$. This suggests that despite the fact that neural and muscular responses were well developed in those young larvae since they were able to react to a visual stimulus, the reception to the sound stimulus was not sufficiently developed to produce a consistent response according to dietary differences. The mechanoreceptive neuromast cells associated with the lateral line system and the inner ear (auditory nerve) are the major receptors for external vibrational and gravitational stimuli in fish. The lateral line system of teleost fish typically consists of a row of pores along the tail, body and head, leading into an underlying fluid-filled lateral line
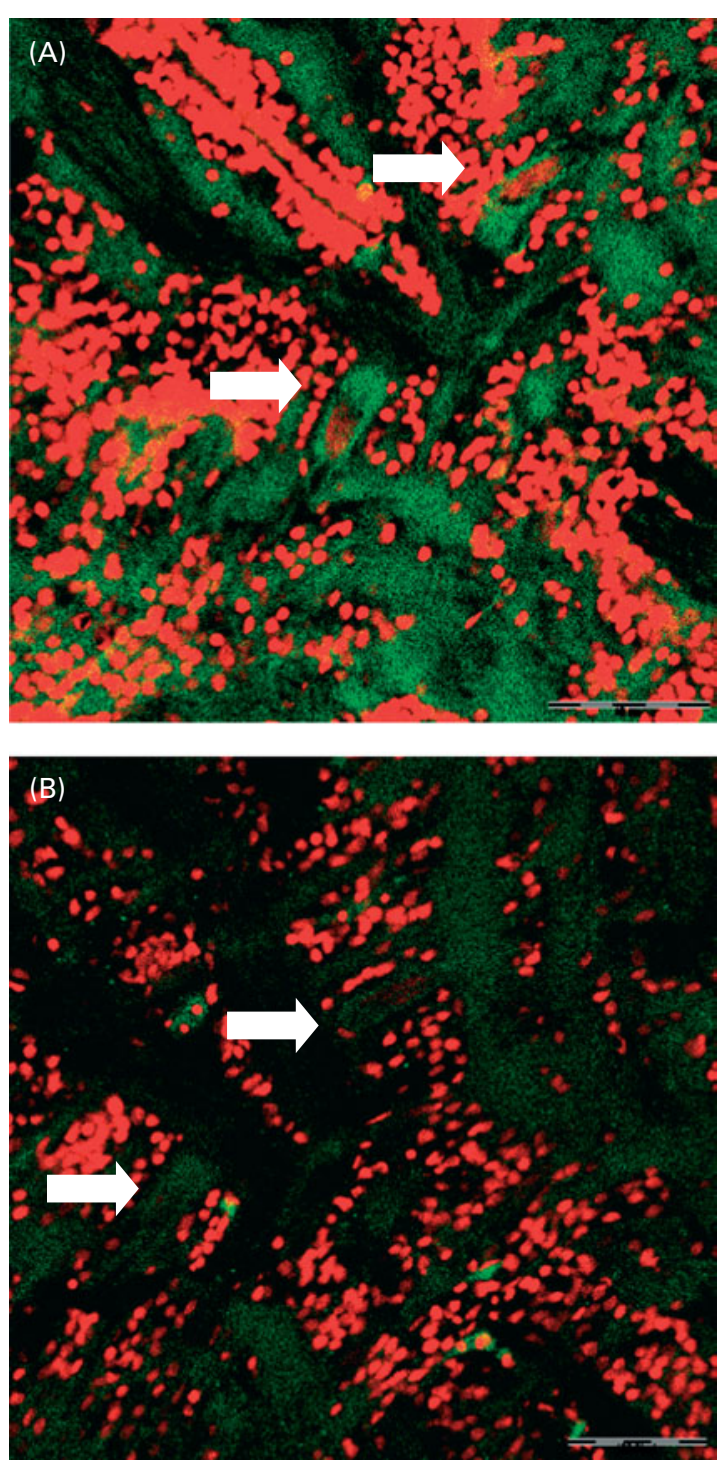

Fig. 3. Confocol microscopy image of the acetylcholine immunopositive response of Mauthner cells longitudinal sections from larvae fed with (A) fish oil microdiet and (B) soyabean oil microdiet. Scale bar $10 \mu \mathrm{m}$. 
Table 2. Fatty acids content (\% total determined fatty acids, $n 3$ ) of $35 \mathrm{~d}$ old sea bream larvae fed with fish oil microdiet (fish oil larvae) and soyabean oil microdiet (soyabean larvae)

(Mean values and standard deviations)

\begin{tabular}{|c|c|c|c|c|}
\hline \multirow[b]{2}{*}{ Fatty acid } & \multicolumn{2}{|c|}{ Fish oil larvae } & \multicolumn{2}{|c|}{ Soyabean oil larvae } \\
\hline & Mean & SD & Mean & SD \\
\hline $14: 0$ & 1.08 & 0.21 & 0.69 & 0.08 \\
\hline $14: 1 n-7$ & $0 \cdot 18$ & 0.02 & $0 \cdot 10$ & 0.02 \\
\hline $14: 1 n-5$ & 0.11 & 0.03 & 0.02 & 0.02 \\
\hline $15: 0$ & 0.32 & 0.03 & 0.27 & 0.02 \\
\hline $15: 1 n-5$ & 0.03 & 0.00 & 0.02 & 0.01 \\
\hline 16 : OISO & 0.08 & 0.01 & 0.06 & 0.02 \\
\hline $16: 0$ & 19.33 & 1.69 & $22 \cdot 66$ & 1.98 \\
\hline $16: 1 n-7$ & 3.64 & 0.15 & 1.66 & 0.19 \\
\hline $16: 1 n-5$ & 0.21 & 0.02 & $0 \cdot 16$ & 0.03 \\
\hline $16: 2 n-6$ & 0.13 & 0.06 & 0.18 & 0.02 \\
\hline $16: 2 n-4$ & 0.50 & $0 \cdot 10$ & 0.26 & 0.03 \\
\hline $17: 00$ & 0.42 & 0.01 & 0.22 & 0.06 \\
\hline $16: 3 n-4$ & 0.06 & 0.02 & 0.02 & 0.00 \\
\hline $16: 3 n-3$ & 0.08 & 0.05 & $N D^{*}$ & - \\
\hline $16: 3 n-1$ & 0.16 & 0.01 & $N D^{*}$ & - \\
\hline $16: 4 n-3$ & 0.65 & 0.11 & 0.67 & 0.05 \\
\hline $16: 4 n-1$ & 0.08 & 0.03 & 0.14 & 0.11 \\
\hline $18: 0$ & $9 \cdot 74$ & 1.24 & 11.73 & 0.32 \\
\hline $18: 1 n-9$ & 9.57 & 0.77 & 12.56 & $2 \cdot 24$ \\
\hline $18: 1 n-7$ & $3 \cdot 84$ & 0.63 & $2 \cdot 35$ & 0.90 \\
\hline $18: 1 n-5$ & 0.33 & 0.05 & 0.35 & 0.08 \\
\hline $18: 2 n-9$ & 0.23 & 0.03 & 0.12 & 0.15 \\
\hline $18: 2 n-6$ & $4.77^{\mathrm{b}}$ & 0.37 & $15 \cdot 37^{a}$ & 0.63 \\
\hline $18: 2 n-4$ & 0.09 & 0.00 & 0.06 & 0.06 \\
\hline $18: 3 n-6$ & $0 \cdot 10$ & 0.03 & 0.11 & 0.01 \\
\hline $18: 3 n-4$ & 0.09 & $0 \cdot 12$ & 0.09 & 0.03 \\
\hline $18: 3 n-3$ & $1 \cdot 19$ & 0.37 & 0.98 & 0.07 \\
\hline $18: 3 n-1$ & 0.06 & 0.00 & $\mathrm{ND}^{*}$ & \\
\hline $18: 4 n-3$ & 0.32 & 0.02 & 0.09 & 0.04 \\
\hline $18: 4 n-1$ & 0.03 & 0.00 & 0.01 & 0.00 \\
\hline $20: 00$ & $0 \cdot 17$ & 0.06 & 0.26 & 0.06 \\
\hline $20: 1 n-9+n-7$ & 1.41 & 0.02 & $1 \cdot 28$ & $0 \cdot 18$ \\
\hline $20: 1 n-5$ & 0.29 & 0.01 & 0.22 & 0.06 \\
\hline $20: 2 n-9$ & $0 \cdot 13$ & 0.02 & $0 \cdot 11$ & 0.02 \\
\hline $20: 2 n-6$ & 0.47 & 0.02 & 0.93 & 0.14 \\
\hline $20: 3 n-6$ & $0 \cdot 16$ & 0.01 & 0.12 & 0.03 \\
\hline $20: 4 n-6$ & 2.43 & 0.13 & 1.7 & 0.13 \\
\hline $20: 3 n-3$ & 0.20 & $0 \cdot 13$ & 0.21 & 0.01 \\
\hline $20: 4 n-3$ & 0.32 & 0.02 & 0.07 & 0.00 \\
\hline $20: 5 n-3$ & $7.44^{\mathrm{a}}$ & 0.07 & $3.53^{b}$ & 0.39 \\
\hline $22: 1 n-11$ & 0.29 & $0 \cdot 20$ & 0.29 & 0.05 \\
\hline $22: 1 n-9$ & 0.11 & 0.04 & 0.10 & 0.02 \\
\hline $22: 4 n-6$ & $0 \cdot 16$ & 0.02 & 0.04 & 0.01 \\
\hline $22: 5 n-6$ & 0.75 & $0 \cdot 11$ & 0.51 & 0.04 \\
\hline $22: 5 n-3$ & $2 \cdot 00$ & 0.11 & 0.67 & 0.01 \\
\hline $22: 6 n-3$ & $26 \cdot 26^{\mathrm{a}}$ & 0.85 & $18 \cdot 86^{\mathrm{b}}$ & 2.03 \\
\hline Saturated & 30.40 & $3 \cdot 19$ & 35.35 & 2.24 \\
\hline Unsaturated & $13 \cdot 40$ & $1 \cdot 19$ & 15.48 & 2.33 \\
\hline Monoenoics & $15 \cdot 56$ & $1 \cdot 19$ & $16 \cdot 93$ & 3.41 \\
\hline Polyunsaturated & 48.84 & 1.82 & 44.87 & 1.53 \\
\hline$n-3$ & 38.45 & 1.42 & 25.08 & 2.51 \\
\hline$n-6$ & 8.97 & 0.50 & 18.99 & 0.89 \\
\hline$n-9$ & 11.45 & 0.65 & $14 \cdot 17$ & 2.59 \\
\hline$n-3$ HUFA & $40 \cdot 35$ & 0.87 & 39.83 & 2.42 \\
\hline AA/EPA & 0.33 & 0.01 & 0.49 & 0.10 \\
\hline EPA/DHA & 0.28 & 0.01 & 0.19 & - \\
\hline
\end{tabular}

$\mathrm{ND}$, not detected.

a,b Mean values within a row with unlike superscript letters were significantly different as determined by Student's $t$ test honestly significant difference ( $n 3$, $P<0.05$ ).

${ }^{*} \mathrm{ND} \leq 0.005$ canal. The neural impulses from these receptors are transmitted along the anterior and posterior lateral line nerves to the octavolateralis area of the medulla ${ }^{(33)}$. In the fish used in the present study the lateral line was better developed, whereas in the former trial, conducted with younger larvae, the lateral line had not started to appear until the end of the experiment (15-20d). A further development of the sensorial organs in the larvae of the present study would allow a different perception of the stimulus by larvae fed different $n$ - 3 LCPUFA suggesting the importance of these fatty acids for the normal functioning of the lateral line.

The Mauthner neurons are known to receive sensory information not only from the auditory nerve ${ }^{(34,35)}$, but also from the optic tectum ${ }^{(36)}$, the lateral line mechanosensory system $^{(37)}$, the somatosensory channels ${ }^{(38)}$ and via the electrosensory system in weakly electric fish ${ }^{(37)}$. Thus, a variety of sensory modalities could modulate the relative excitation or inhibition of the M-cells before a startling stimulus driving it beyond threshold levels. Escaping behaviour in fish has been particularly related to M-cells. This pair of reticulospinal neurons initiates fast startle responses in fishes and amphibians and constitutes an important model system in the studies of vertebrate neurons and their control of behaviour ${ }^{(16)}$. In the present study, faster startle response in fish fed $n$-3 LCPUFA was also associated with an increased immunopositive neural response, particularly in M-cells, denoting a higher production of acetylcholine. Acetylcholine release in the hippocampus has been found to be reduced under neuronal activation in rats receiving a chronically $n-3$ PUFA-deficient $\operatorname{diet}^{(25,39)}$. n-3 LC-PUFA, and particularly DHA, markedly affect membrane fluidity and functioning and have been found to be important for neurocyte myelination and synapse construction, with both functions being sensitive to nutritional deficiencies $^{(40)}$. Moreover, these fatty acids are nutritional antioxidants that prevent the formation of cerebral lipid peroxides $^{(41)}$, stabilising the oxidant/antioxidant status of the membrane structures in the brain ${ }^{(42)}$, and protecting them from several neurological and neuropsychiatric disorders ${ }^{(43)}$ Most of the DHA accumulation occurs during late pre-natal and early post-natal development, coinciding with the formation of synapses ${ }^{(44)}$. Similarly, DHA accumulates in the brain and the sensorial organs of the fish during larval development and it is retained in the neural tissues even during periods of starvation ${ }^{(32,45)}$. Adequate dietary availability of DHA during this period is essential for optimal development and functioning of the central nervous system. Inadequate intake of DHA is thus associated with impaired attention and learning performance as well as modifications in emotional status including elevated behavioural indices of anxiety, aggression and depression ${ }^{(46)}$.

The present study shows the first evidence of the importance of $n-3$ LCPUFA for the adequate functioning of particular neurons, the M-cells, and, subsequently, for the behavioural response that they modulate to escape from a sound stimulus. Further studies are being conducted to understand the role of these essential fatty acids on neural development and functioning. 


\section{Acknowledgements}

A doctoral scholarship from the Canarian Government supported the present study. The experiments were designed according to the Animal Welfare Ethics Committee guidelines of Las Palmas de Gran Canaria University. T. B. S. carried out the animal experiment, performed the biochemical and immunofluorescence studies, participated in the interpretation of the results and drafted the manuscript. E. J. C. participated in the design of the study and took part in animal feeding and sampling. M. B., S. T. and M. J. C. participated in the immunofluorescence studies and result interpretation. M. S. I. conceived the study and its design, coordinated the work, and participated in the interpretation of the results and the preparation of the manuscript. All the authors read and approved the final manuscript. There are no potential conflicts of interest.

\section{References}

1. Uauy R \& Dangour AD (2006) Nutrition in brain development and aging: role of essentials fatty acids. Nutr Rev $\mathbf{6 4}$ 5 Pt 2, S24-S33.

2. Guesnet P \& Alessandri JM (2010) Docosahexaenoicacid (DHA) and the developing central nervous system (CNS) implications for dietary recommendations. Biochimie $\mathbf{9 3}$ $7-12$.

3. Robson LG, Dyall S, Sidloff D, et al. (2010) Omega-3 polyunsaturated fatty acids increase the neurite outgrowth of rat sensory neurones throughout development and in aged animals. Neurobiol Aging 31, 678-687.

4. Yamamoto N, Hashimoto A, Takemoto Y, et al. (1988) Effect of dietary alpha-linolenate/linoleate balance on brain lipid compositions and learning ability of rats. II: Discrimination process, extinction process, and glycolipid compositions. J Lipid Res 29, 1013-1021.

5. Bourre JM, Francois M, Youyou A, et al. (1989) The effects of dietary $(\alpha$-linolenic acid on the composition of nerve membranes, enzymatic activity, amplitude of electrophysiological parameters, resistance to poisons and performance of learning tasks in rats. J Nutr 119, 1880-1892.

6. Neuringer M, Connor WE, Lin DS, et al. (1986) Biochemical and functional effects of prenatal and post natal $n-3$ fatty acid deficiency on retina and brain in rhesus monkey. Proc Nat Acad Sci USA 83, 4021-4025.

7. Neuringer M, Reisbeck S \& Janowsky J (1994) The role of $n-3$ fatty acids in visual and cognitive development: current evidence and methods of assessment. Pediatr 125, Suppl., 39-47.

8. Izquierdo MS, Watanabe T, Takeuchi T, et al. (1989) Optimal EFA levels in Artemia to meet the EFA requirements of red seabream Pagrus major. In The Current Status of Fish Nutrition in Aquaculture, pp. 221-232 [M Takeda and $\mathrm{T}$ Watanabe, editors]. Tokyo: Japan Translation Centre.

9. Izquierdo MS (1996) Essential fatty acid requirements of cultured marine fish larvae. Aquacult Nutr 2, 183-191.

10. Watanabe T \& Kiron V (1994) Prospects in larval fish dietetics. Aquaculture 124, 223-251.

11. Izquierdo MS, Socorro J, Arantzamendi L, et al. (2000) Recent advances in lipid nutrition in fish larvae. Fish Physiol Biochem 22, 97-107.

12. Masuda R, Takeuchi T, Tsukamoto K, et al. (1999) Incorporation of dietary docosahexaenoic acid into the central nervous system of the yellowtail Seriola quinqueradiata. Brain Behav Evol 53, 173-179.

13. Benítez-Santana T, Masuda R, Valencia A, et al. (2007) Dietary n-3 HUFA deficiency induces a reduced visual response in gilthead seabream Sparus aurata larvae. Aquaculture 264, 408-417.

14. Bell MV, Batty RS, Dick JR, et al. (1995) Dietary deficiency of docosahexaenoic acid impairs vision at low light intensities in juvenile herring (Clupea harengus L.). Lipids 30, 443-449.

15. Masuda R, Shoji J, Aoyama M, et al. (2002) Chub mackerel larvae fed fish larvae can swim faster than those fed rotifers and Artemia nauplii. Fish Sci 68, 320-324.

16. Korn H \& Faber DS (2005) The Mauthner cell half a century later: a neurobiological model for decision making? Neuron 47, 13-28.

17. Faber DS, Fetcho JR \& Korn H (1989) Neuronal networks underlying the escape response in goldfish: general implications for motor control. Ann NY Acad Sci 563, 11-33.

18. Eaton RC, Lee RKK \& Foreman MB (2001) The Mauthner cell and other identified neurons of the brainstem escape network of fish. Prog Neurobiol 63, 467-485.

19. Svoboda KR \& Fetcho JR (1996) Interactions between the neural networks for escape and swimming in goldfish. J Neurosci 16, 843-852.

20. Zottoli SJ (1977) Correlation of the startle reflex and Mauthner cell auditory responses in unrestrained goldfish. $J$ Exp Biol 66, 243-254.

21. Eaton RC, DiDomenico R \& Nissanov J (1988) Flexible body dynamics of the goldfish C-start: implications for reticulospinal command mechanisms. J Neurosci 8, 2758-2768.

22. Canfield JG \& Rose GJ (1996) Hierarchical sensory guidance of Mauthner-mediated escape responses in goldfish (Carassius auratus) and cichlids (Haplochromis burtoni). Brain Behav Evol 48, 137-156.

23. Weiss SA, Zottoli SJ, Faber DS, et al. (2004) Chronic medullary recordings from freely swimming fish during the C-start escape. Soc Neurosci (abstr no. 672.4).

24. Foreman MB \& Eaton RC (1993) The direction change concept for reticulospinal control of goldfish escape. J Neurosci 13, 4104-4113.

25. Aïd S, Vancassel S, Poumes-Ballihaut C, et al. (2003) Effect of a diet-induced $n$-3 PUFA depletion on cholinergic parameters in the rat hippocampus. J Lipid Res 44, 1545-1551.

26. Atalah E, Hernández-Cruz CM, Benítez-Santana $\mathrm{T}$, et al. (2010) Importance of the relative levels of dietary arachidonic acid and eicosapentaenoic acid for culture performance of gilthead seabream (Sparus aurata) larvae. Aquaculture Res $1-10$.

27. Folch J, Lees M \& Stanley GHS (1957) A simple method for the isolation and purification of total lipids from animal tissues. J Biol Chem 226, 497-509.

28. Christie WW (1982) Lipid Analysis. Oxford: Pergamon Press.

29. Izquierdo MS, Watanabe T, Takeuchi T, et al. (1990) Optimum EFA levels in Artemia to meet the EFA requirements of red sea bream (Pagrus major). In The Current Status of Fish Nutrition in Aquaculture, pp. 221-232 [M Takeda and T Watanabe, editors]. Tokyo: Tokyo University of Fisheries.

30. Yehuda S, Rabinovitz S \& Mostofsky DI (2005) Essential fatty acids and the brain: from infancy to aging. Neurobiol Aging 26, 98-102.

31. Jump DB (2002) Dietary polyunsaturated fatty acids and regulation of gene transcription. Curr Opin Lipidol 13, $155-164$.

32. Izquierdo MS (2005) Essential fatty acid requirements in Mediterranean finfish species. Cah Options Mediterr 63, 91-102. 
33. Bleckmann H, Bullock TH \& Jorgensen JM (1987) The lateral line mechanoreceptive mesencephalic, diencephalic, and telencephalic regions in the thornback ray, Platyrbinoidis triseriata (Elasmobranchii). J Comp Physiol 161, 67-84.

34. Faber DS, Korn H \& Lin JW (1991) Role of medullary networks and postsynaptic membrane properties in regulating Mauthner cell responsiveness to sensory excitation. Brain Behav Evol 37, 286-297.

35. Zottoli SJ, Bentley AP, Prendergast BJ, et al. (1995) Comparative studies on the Mauthner cell of teleost fish in relation to sensory input. Brain Behav Evol 46, 151-164.

36. Canfield JG (2003) Temporal constraints on visually directed C-start responses: behavioral and physiological correlates. Brain Behav Evol 61, 148-158.

37. Zottoli SJ \& Danielson PD (1989) The lateral line afferent and efferent systems of the goldfish with special reference to the Mauthner cell. In The Mechanosensory Lateral Line: Neurobiology and Evolution, pp. 461-478 [S Coombs, P Görner and H Münz, editors]. New York, NY: Springer.

38. Chang YT, Lin JW \& Faber DS (1987) Spinal inputs to the ventral dendrite of the teleost Mauthner cell. Brain Res 417, 205-213.

39. Kodas E, Galineau L \& Bodard S (2004) Serotoninergic neurotransmission is affected by $n-3$ polyunsaturated fatty acids in the rat. $J$ Neurochem $\mathbf{8 9}, 695-702$.
40. Krigman MR \& Hogan EL (1976) Undernutrition in the developing rat: effect upon myelination. Brain Res 107, 239-255.

41. Choin-Kwon S, Park KA, Lee HJ, et al. (2004) Temporal changes in cerebral antioxidant enzyme activities ischemia and reperfusion in a rat focal brain ischemia model: effect of dietary fish oil. Brain Res Dev Brain Res 152, 11-18.

42. Sarsilmaz M, Songur A, Ozyurt H, et al. (2003) Potential role of dietary omega-3 essential fatty acids on some oxidant/ antioxidant parameters in rat's corpus striatum. Prostaglandins Leukot Essent Fatty Acids 69, 253-259.

43. Black KL, Hoff JT, Radins NS, et al. (1984) Eicosapentaenoic acid: effect on brain prostaglandins, cerebral blood flow and edema in ischemic gerbils. Stroke 15, 65-69.

44. Green P, Glozman S, Kamensky B, et al. (1999) Developmental changes in rat brain membrane lipids and fatty acids: the preferential prenatal accumulation of docosahexaenoic acid. J Lipid Res 40, 960-966.

45. Izquierdo MS, Tandler A, Salhí M, et al. (2001) Influence of dietary polar lipids quantity and quality on ingestion and assimilation of labelled fatty acids by larval gilthead seabream. Aquacult Nutr 6, 153-160.

46. Fedorova I \& Salem N (2006) Omega-3 fatty acids and rodent behaviour. Prostaglandins Leukot Essent Fatty Acids $\mathbf{7 5}$ 271-289. 